\title{
Constrained Bernstein - Jacobi hybrid polynomial curves approximation of rational Bezier curves using reparameterization
}

Mao Shi ${ }^{1}$

${ }^{1}$ Shaanxi Normal University

May 6, 2020

\begin{abstract}
Rational B \'\{e\}zier curve; Polynomial approximation; Constrained Jacobian polynomials; Hybrid curve
\end{abstract}

\section{Hosted file}

M.pdf available at https://authorea.com/users/317566/articles/447622-constrainedbernstein-jacobi-hybrid-polynomial-curves-approximation-of-rational-bezier-curves-usingreparameterization

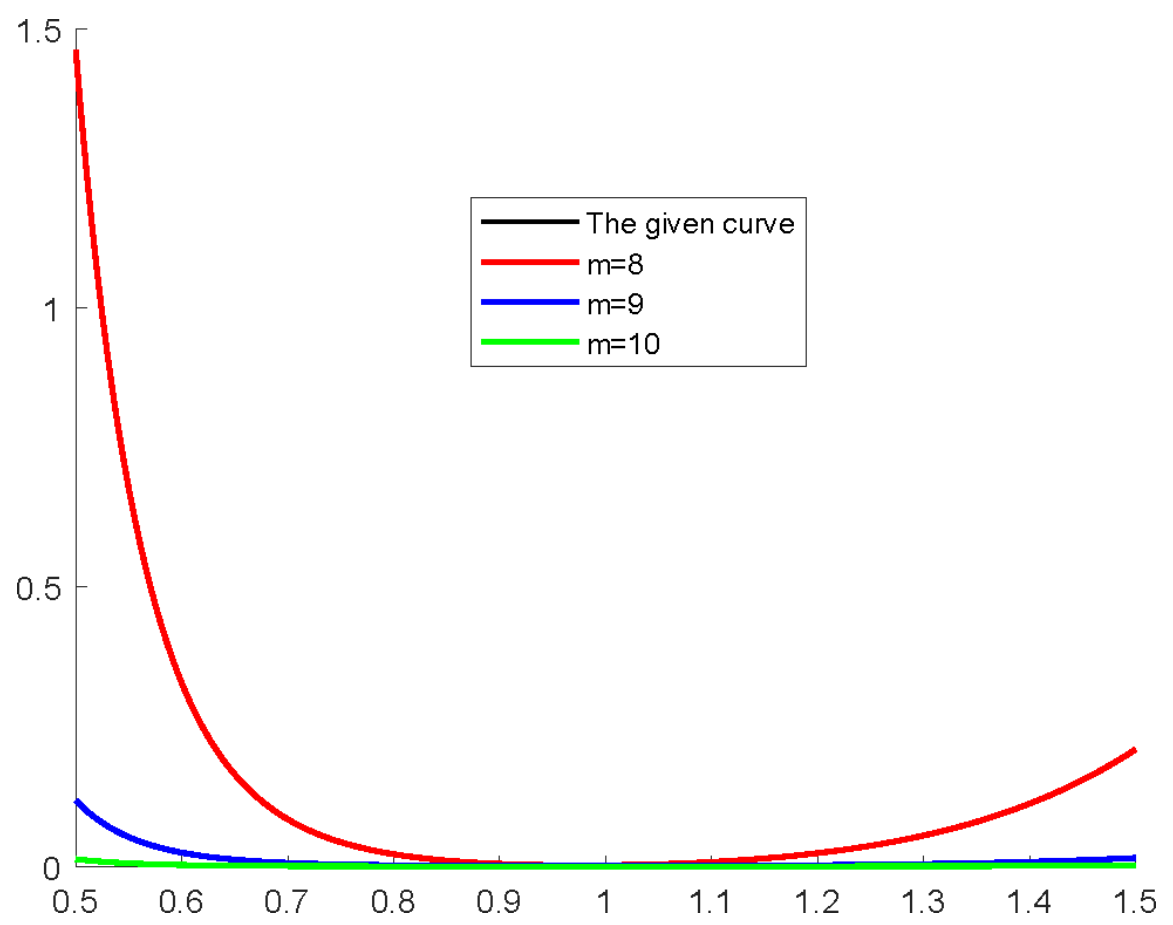




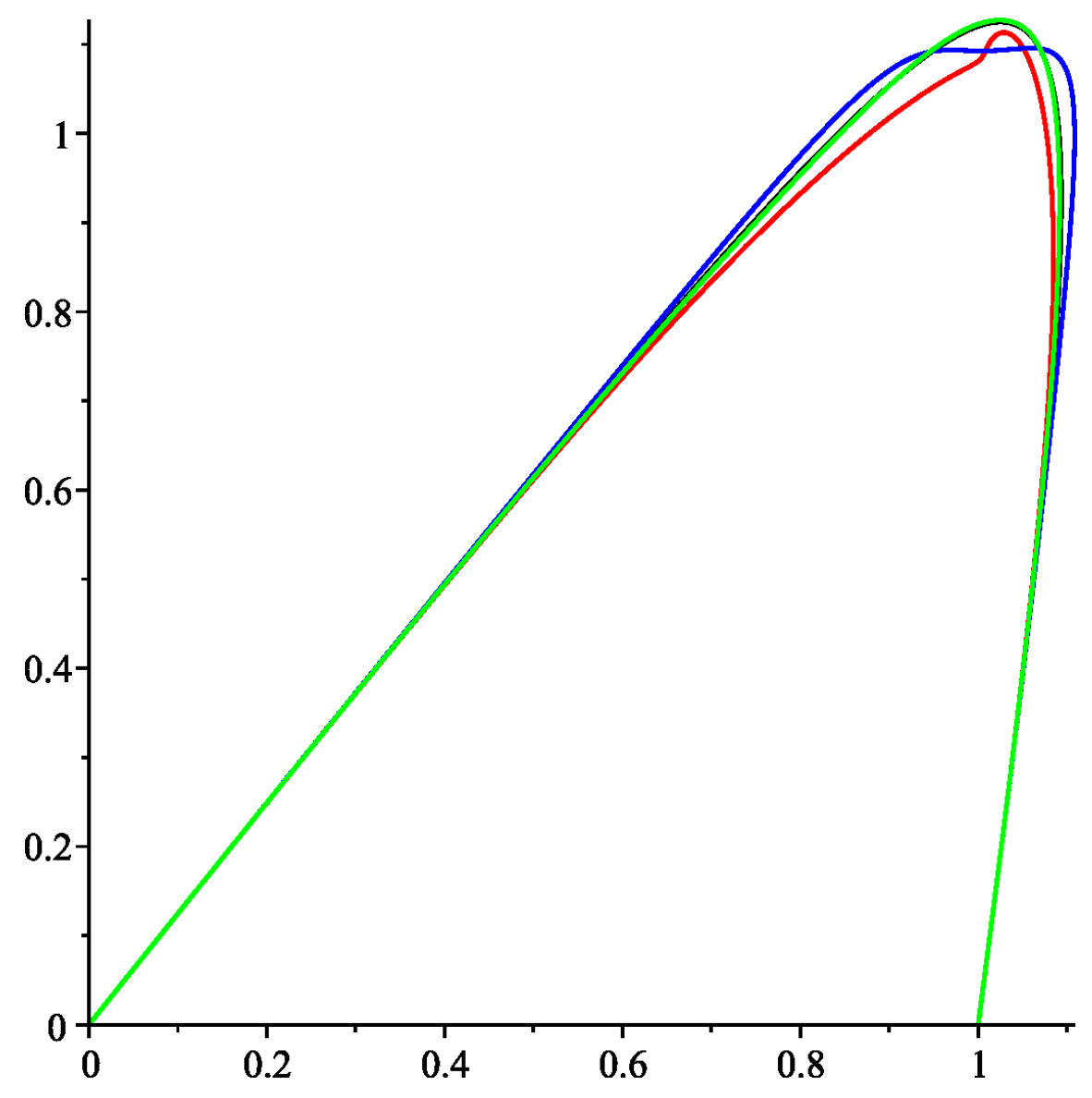



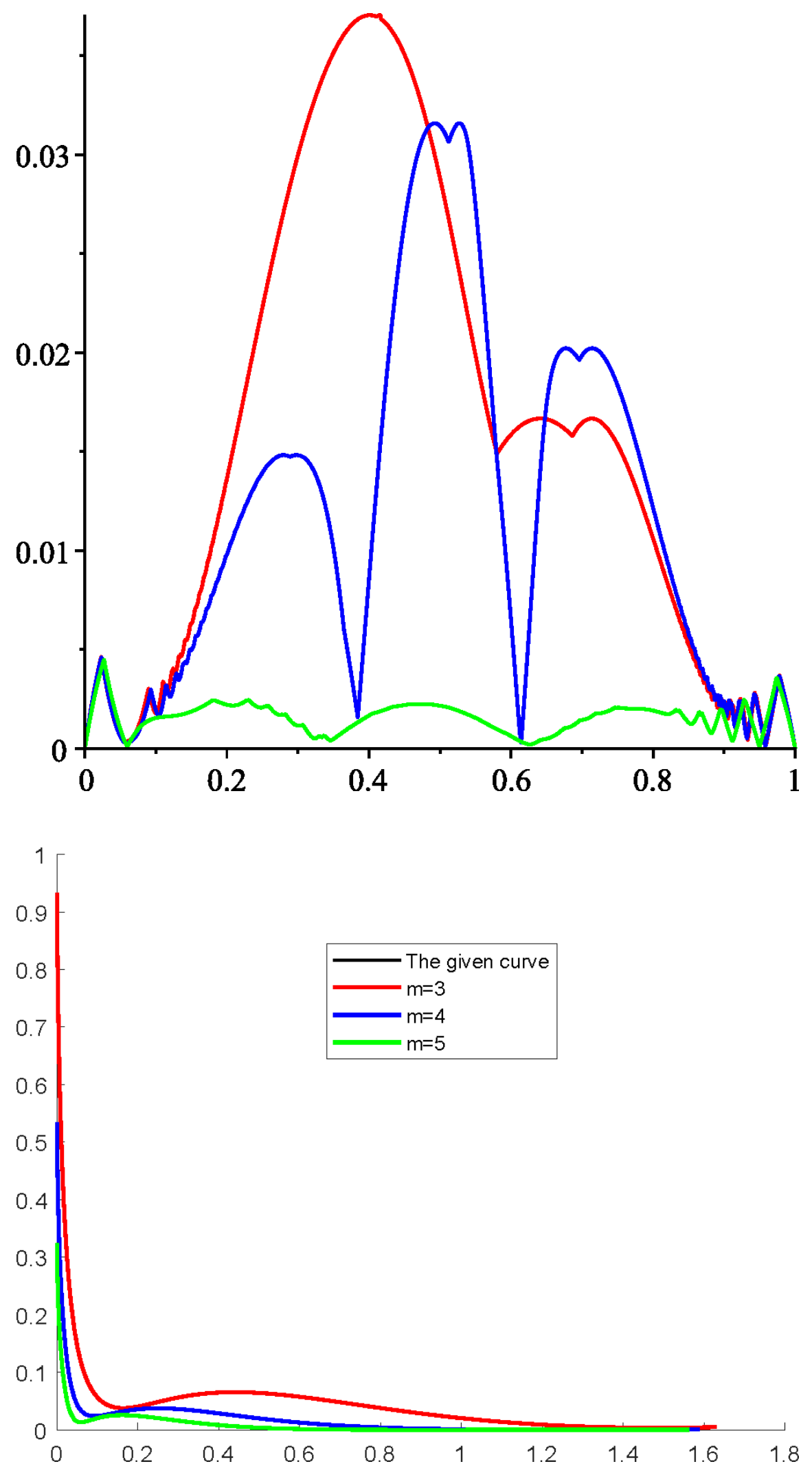


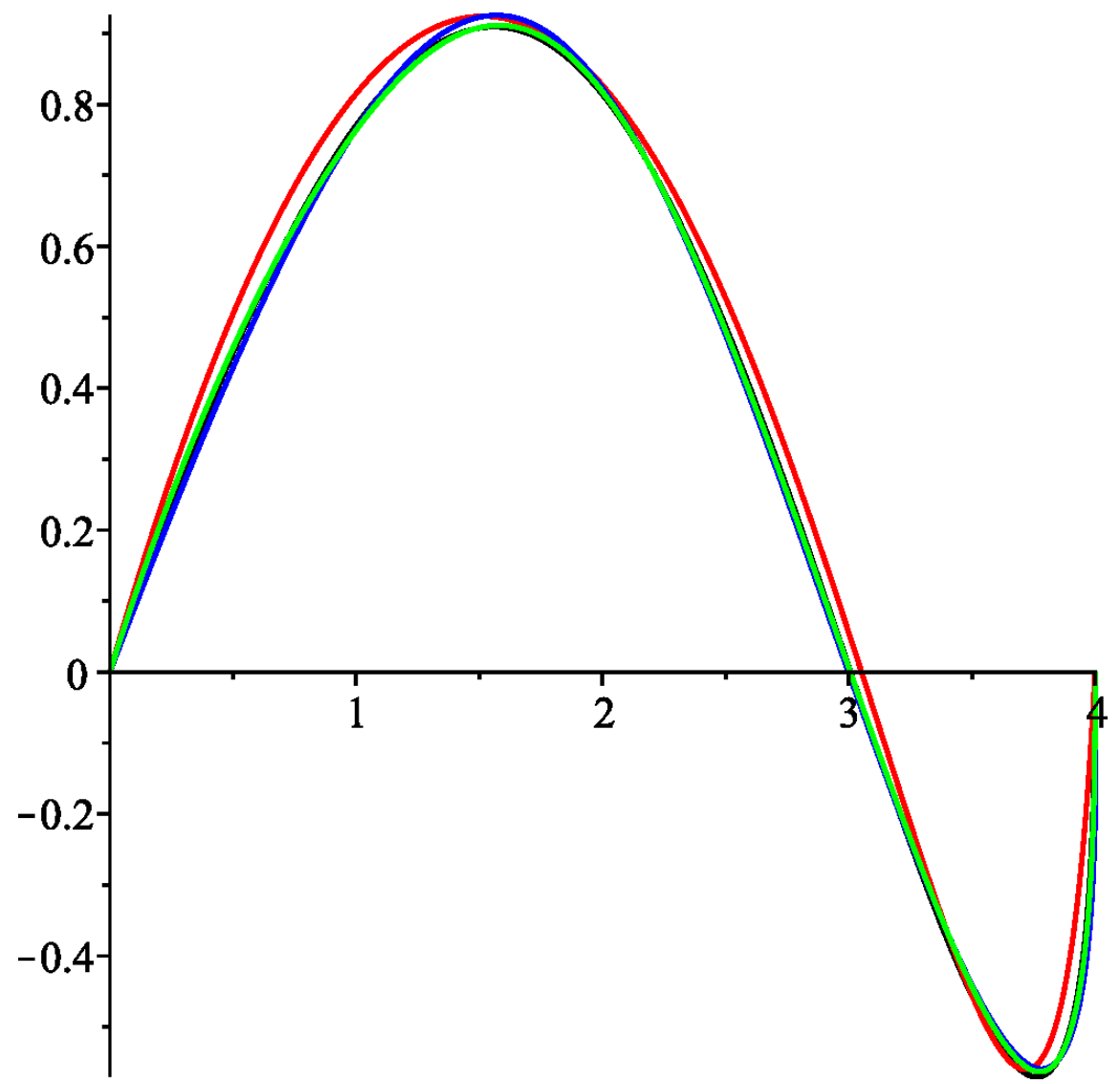




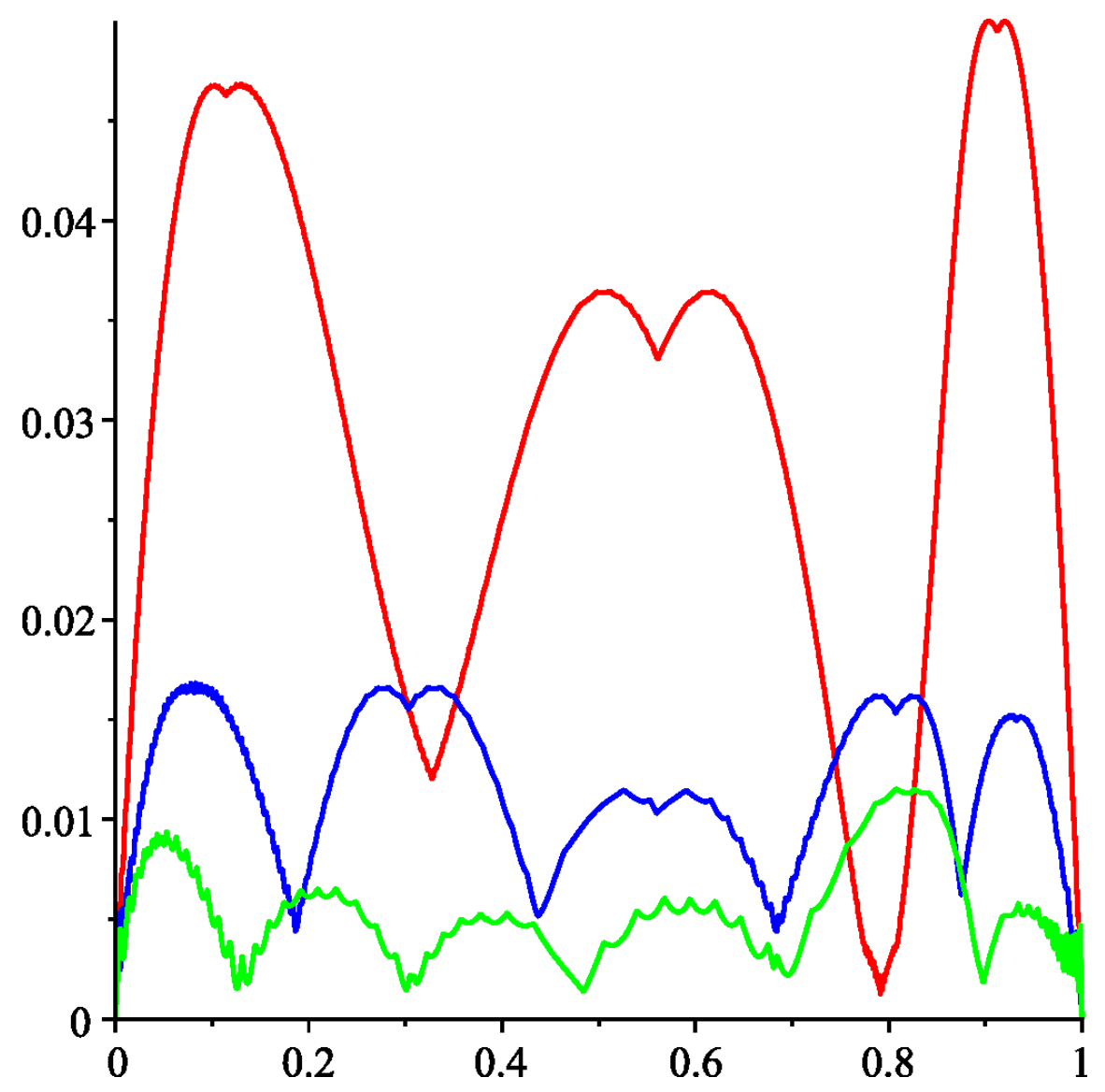




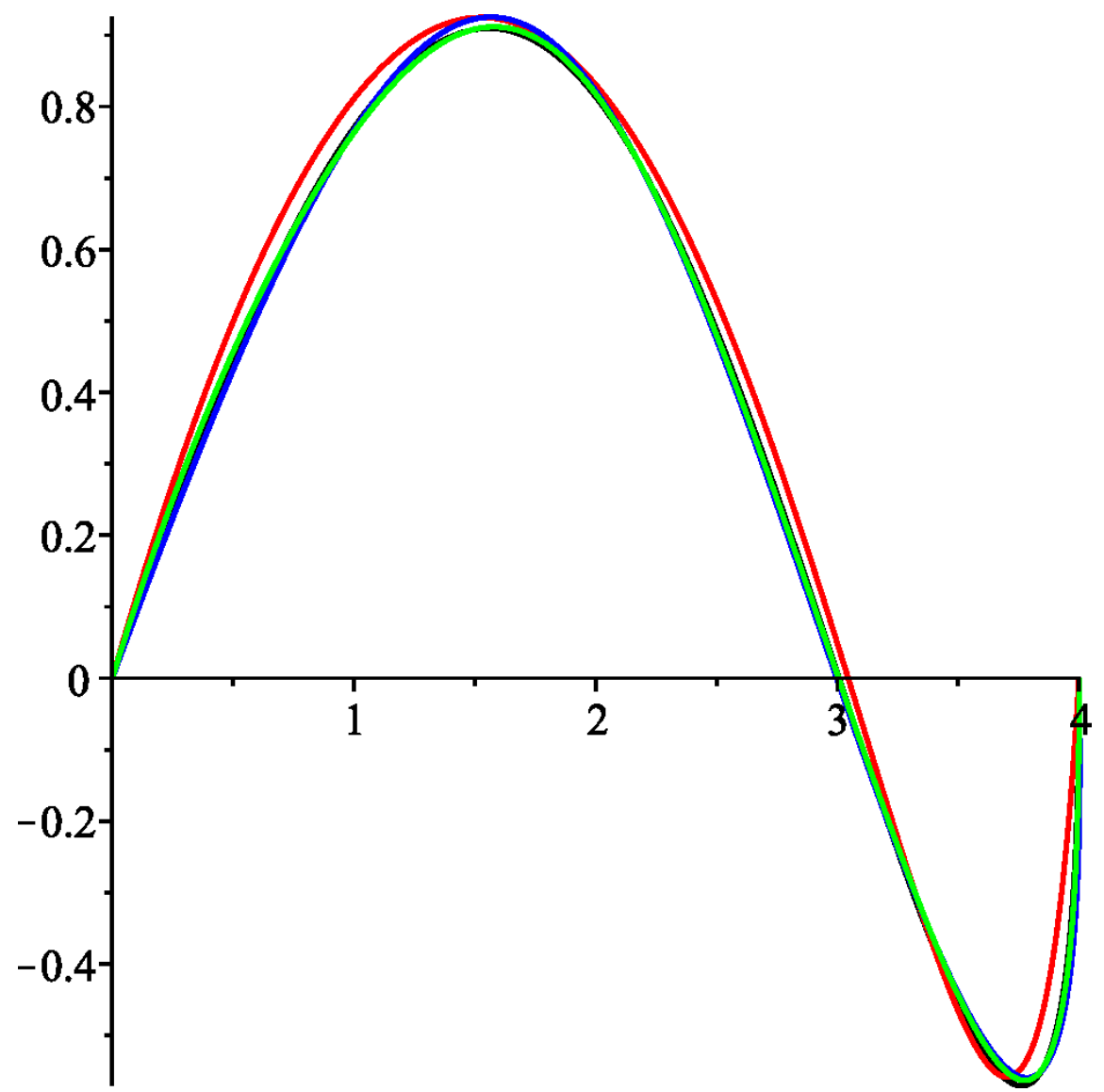



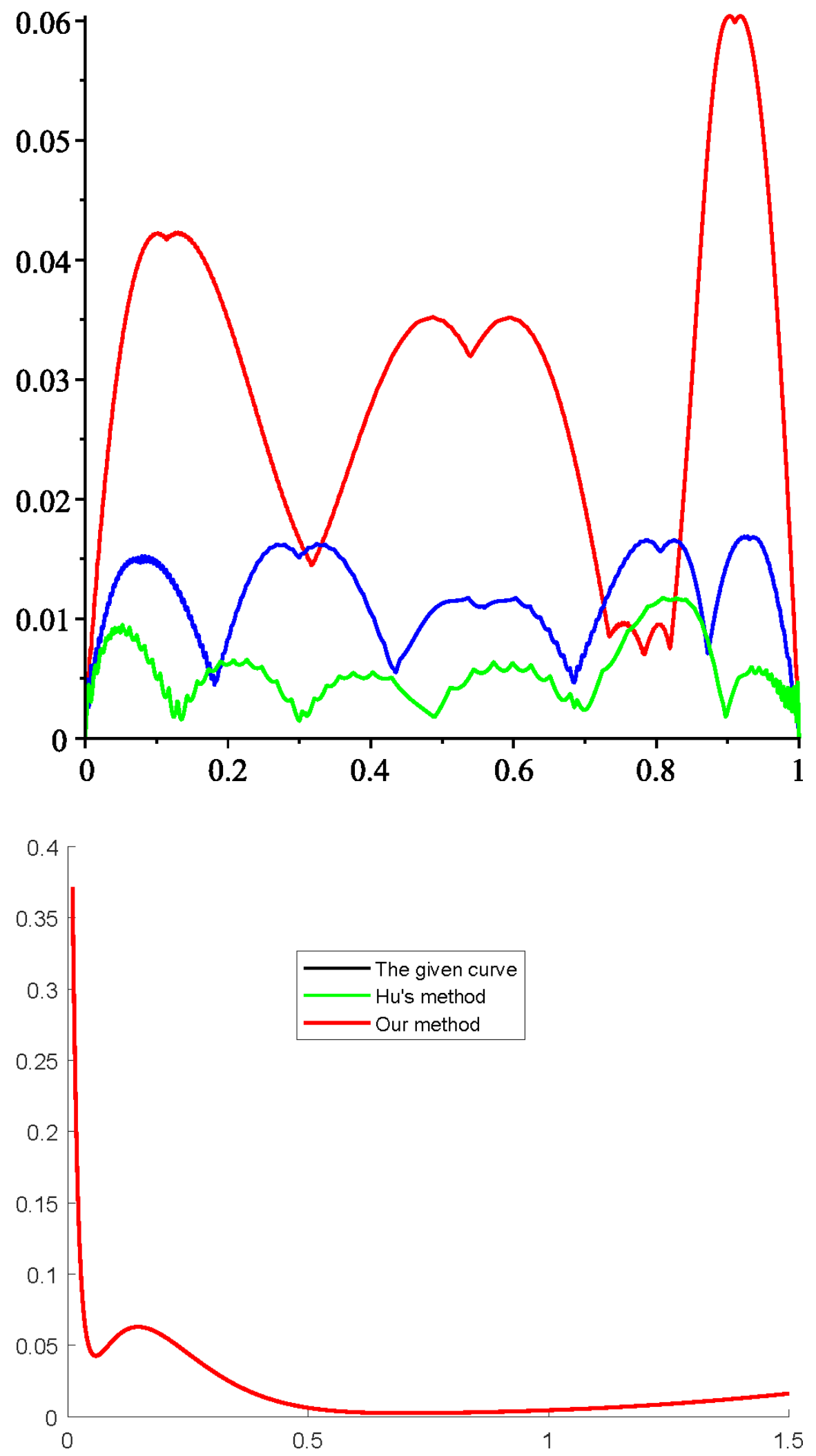


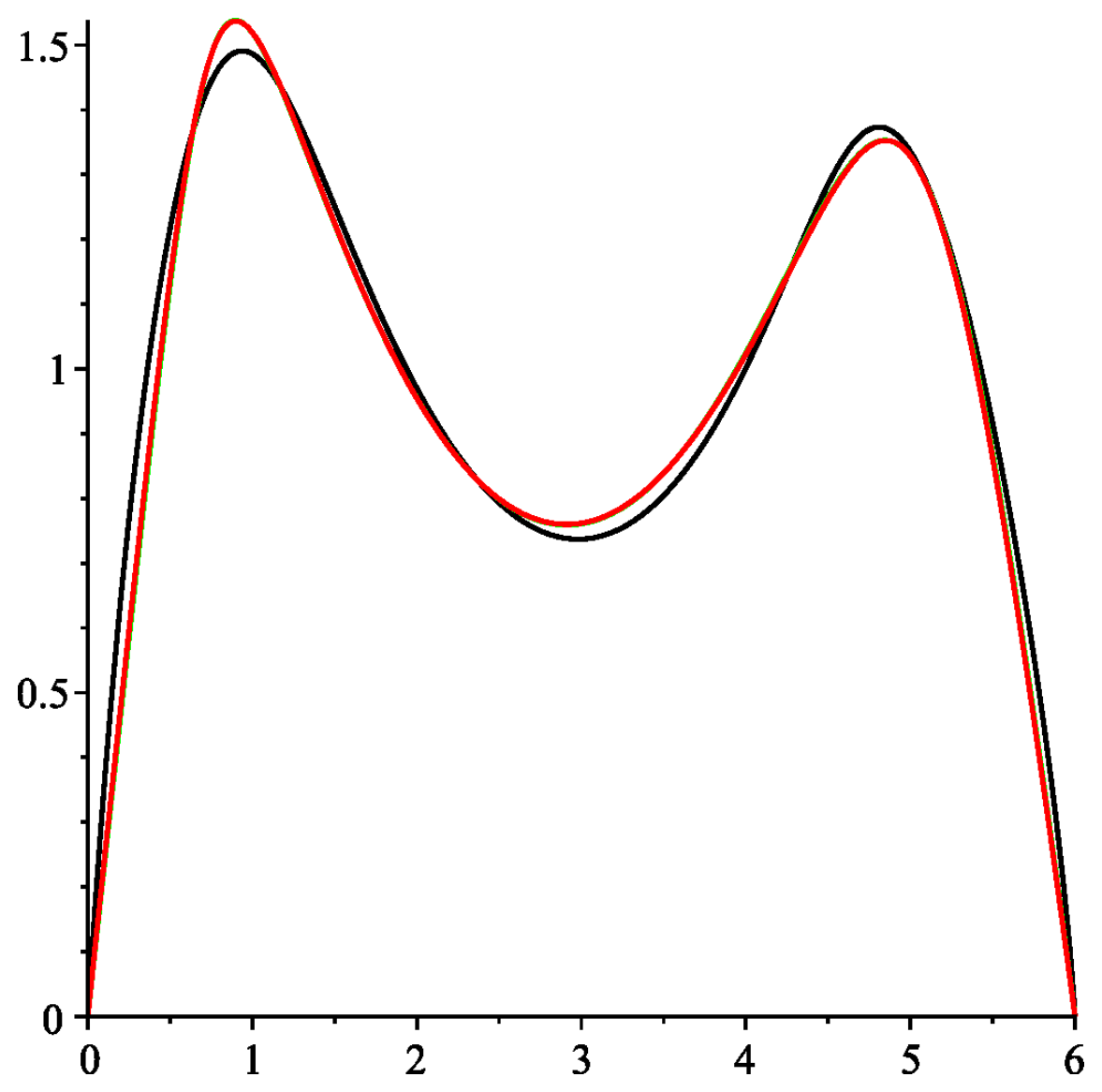



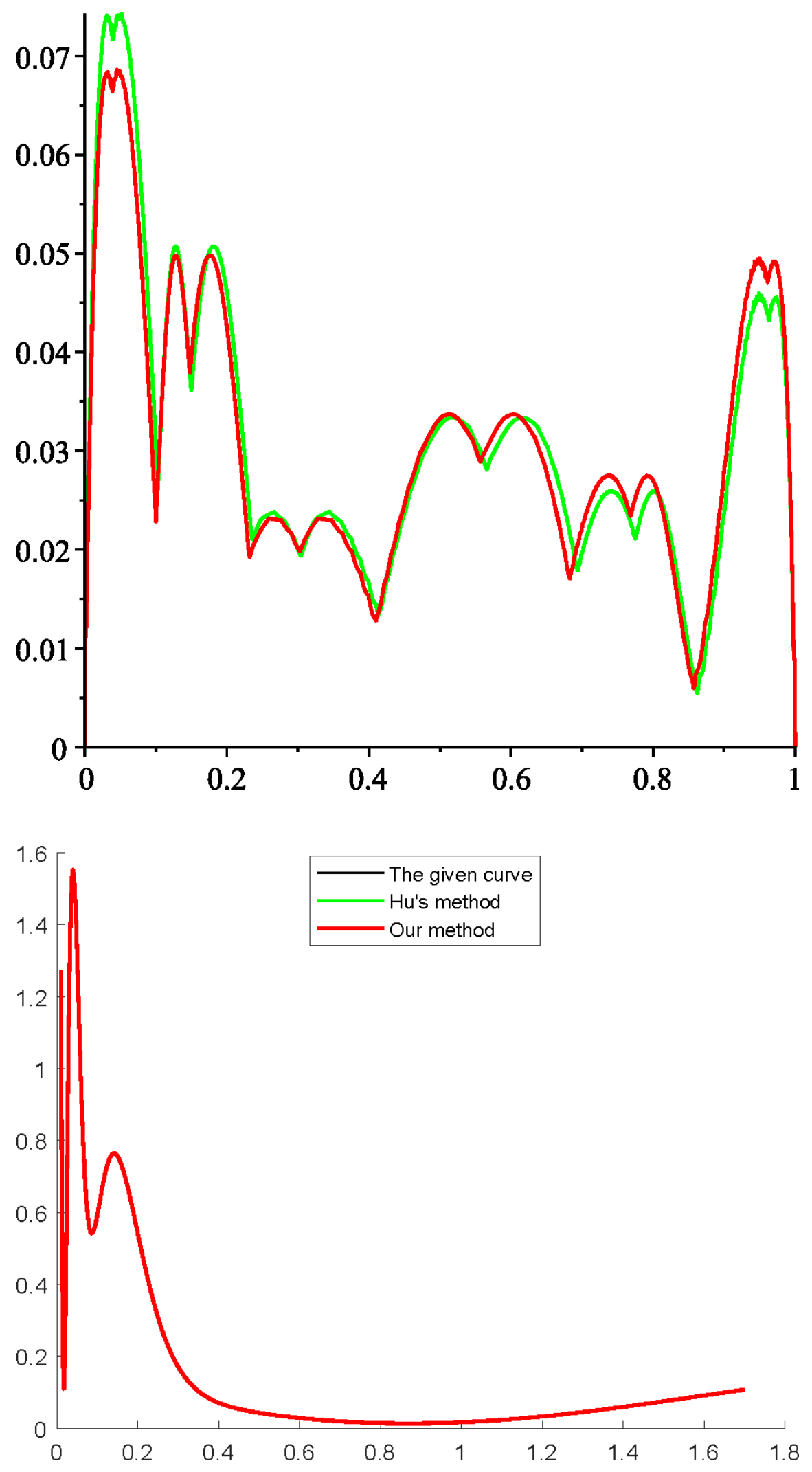


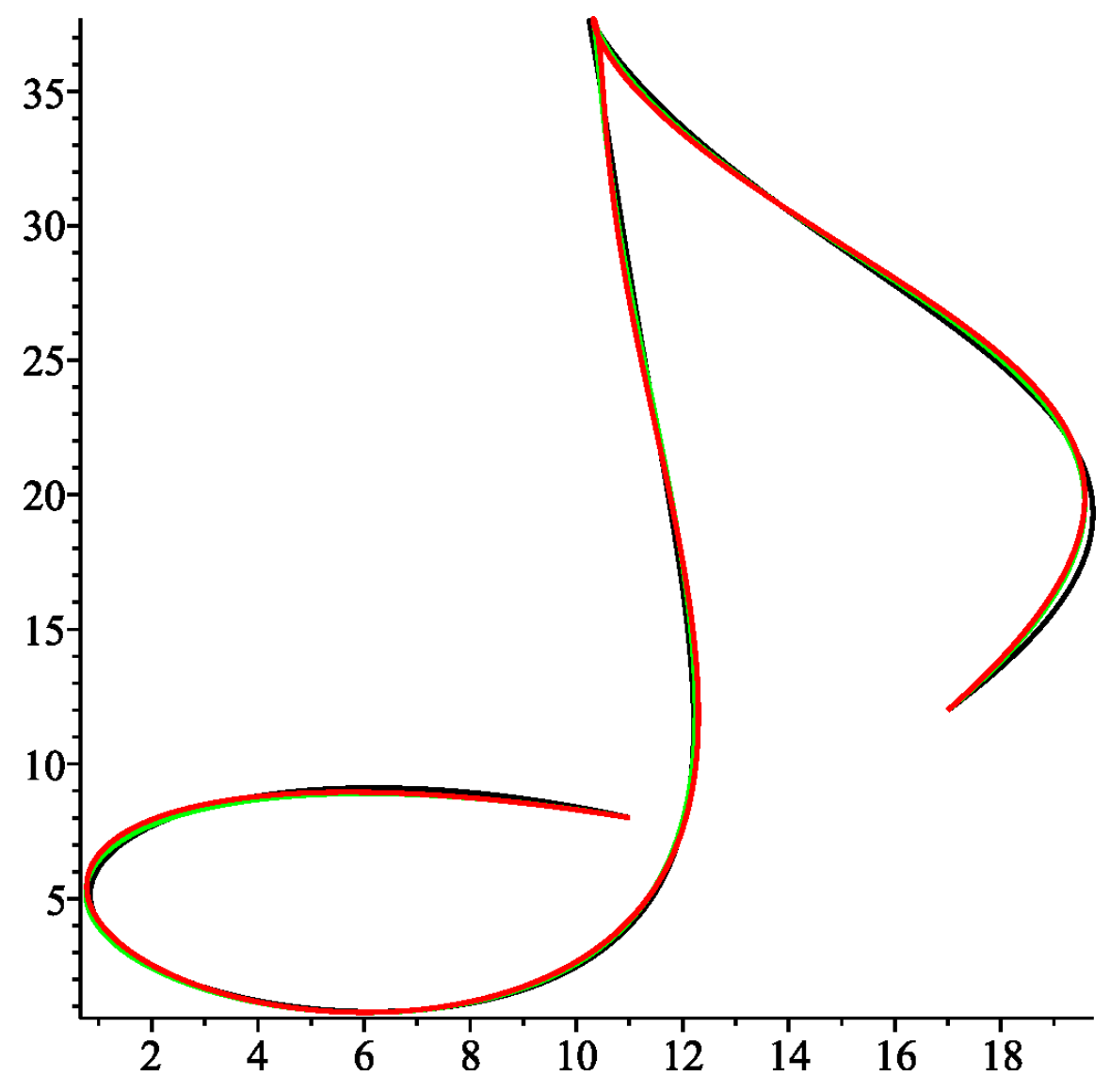



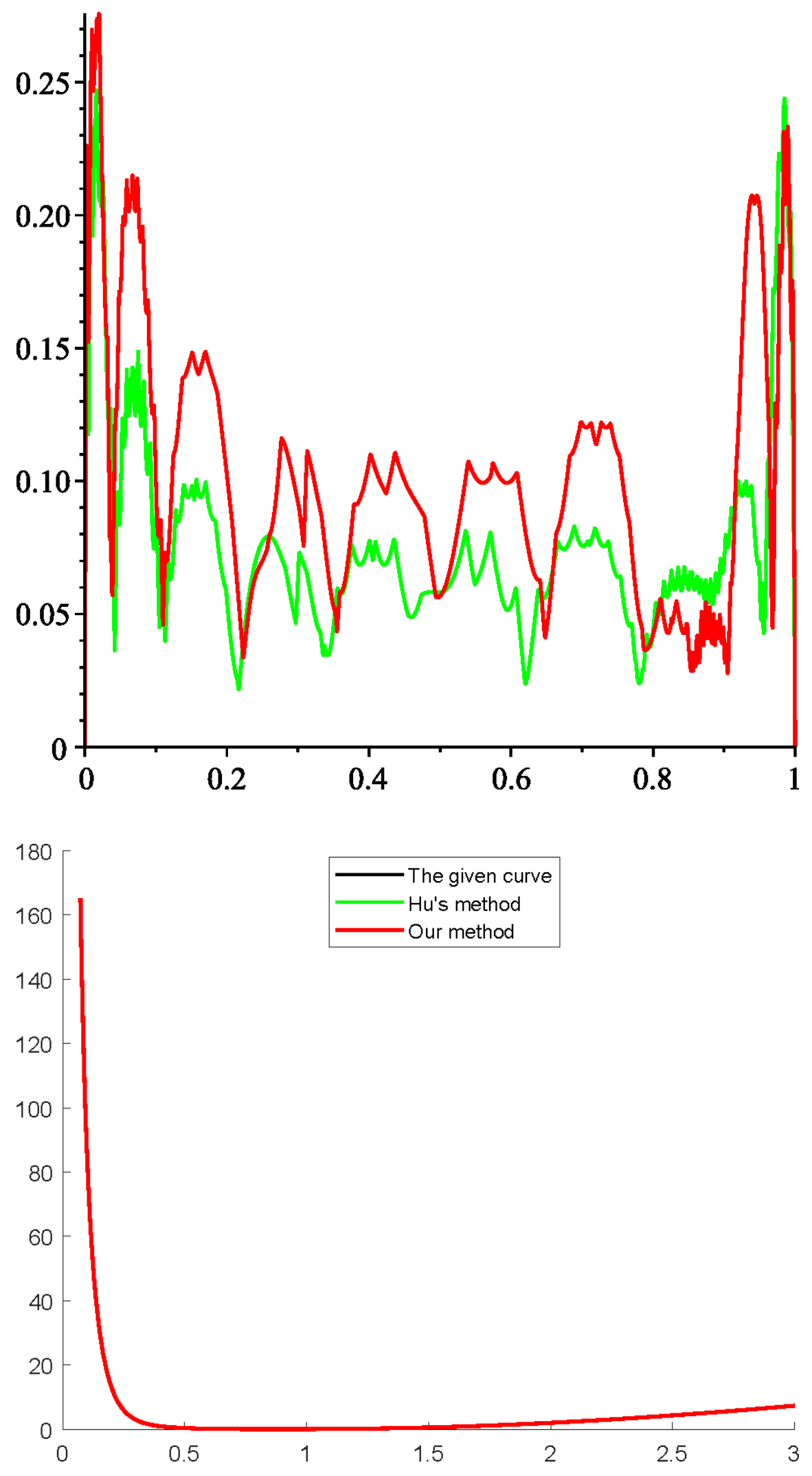


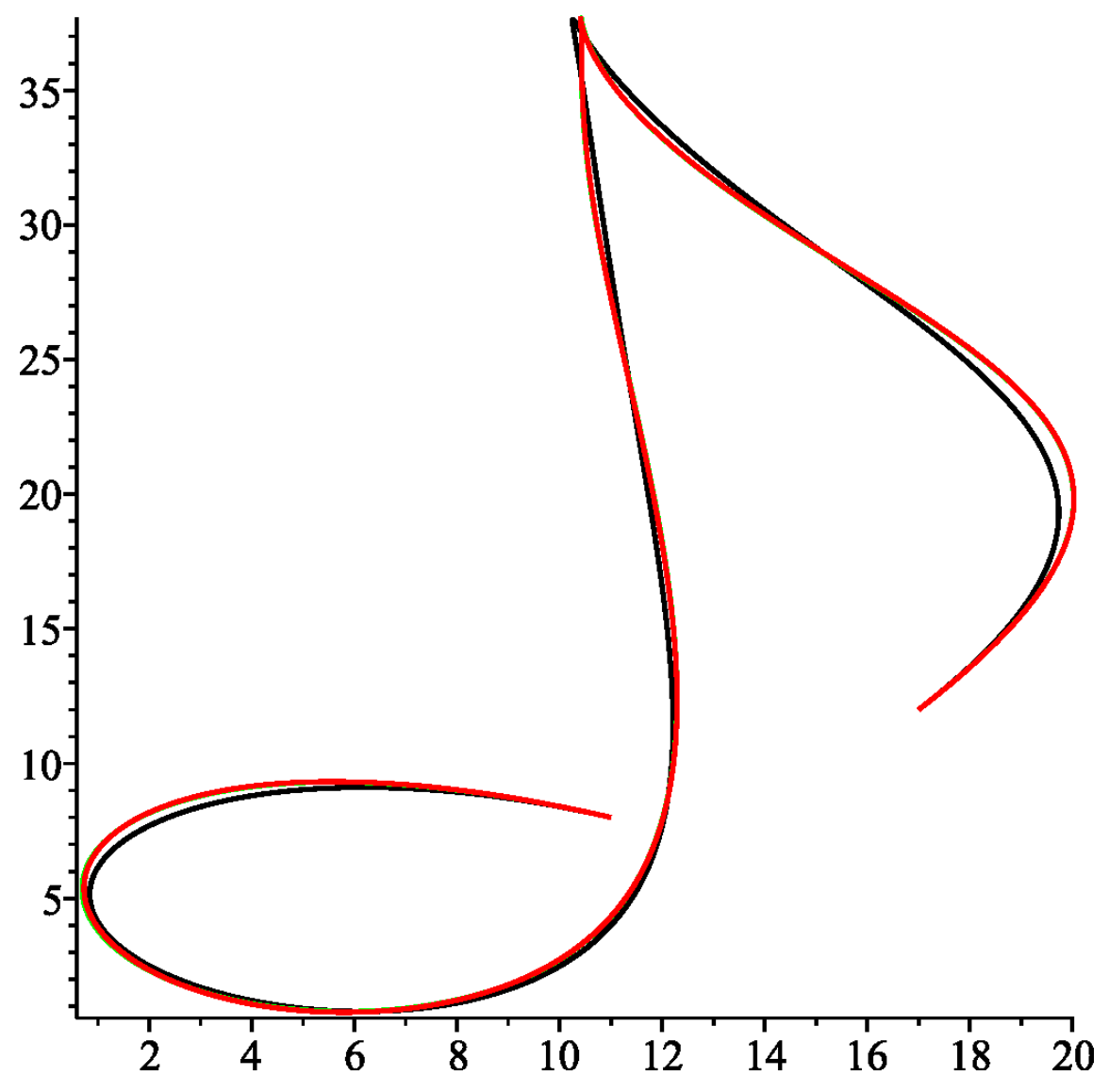




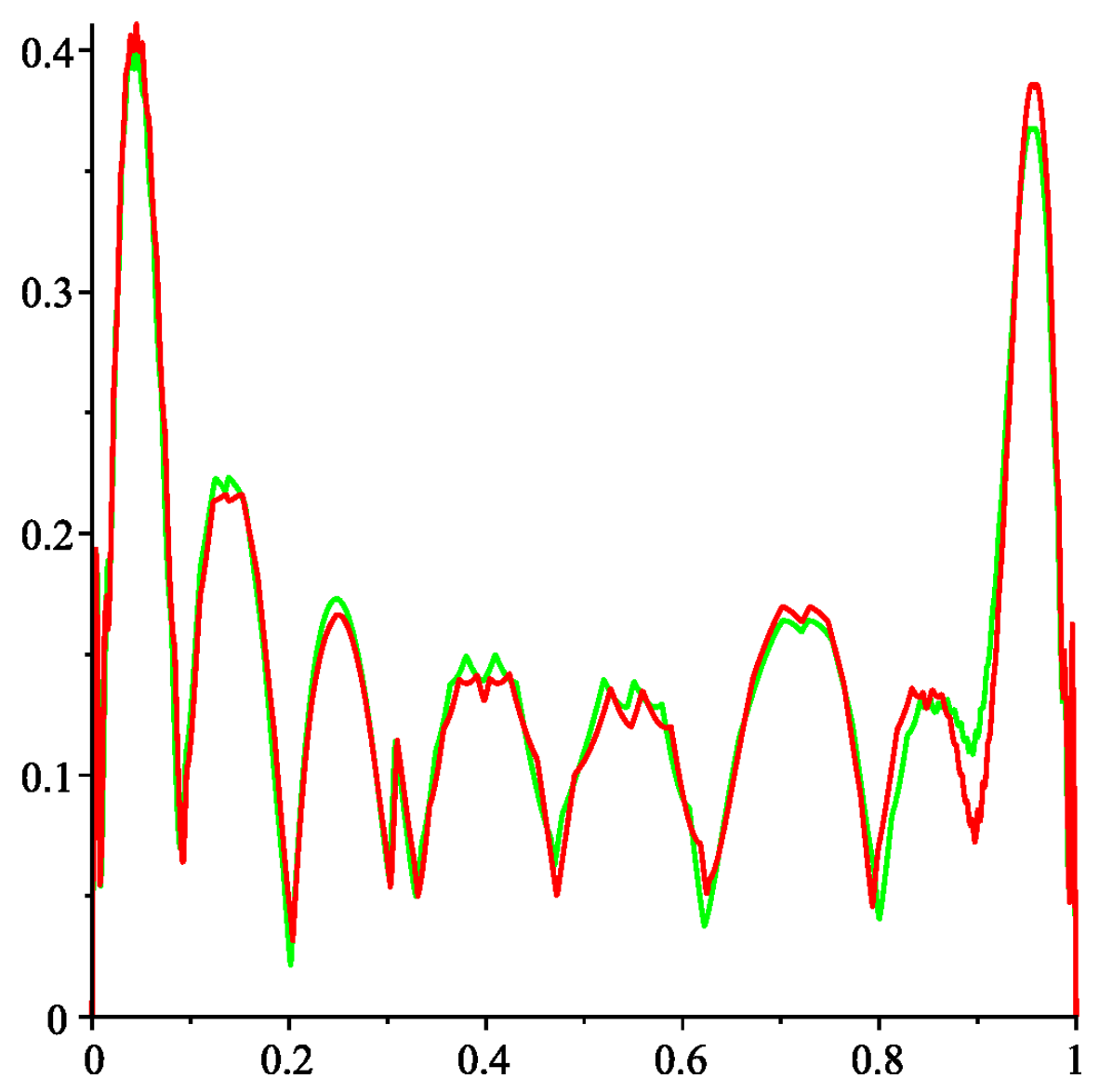

